\title{
Issues Affecting Medication-Taking Behavior of People with Type 2 Diabetes in Indonesia: A Qualitative Study
}

\section{Anna Wahyuni Widayanti \\ Kristian Kalvin Sigalingging (DD \\ Furi Patriana Dewi \\ Niken Nur Widyakusuma}

Department of Pharmaceutics, Faculty of Pharmacy, Universitas Gadjah Mada, Yogyakarta, Indonesia
Correspondence: Anna Wahyuni Widayanti Department of Pharmaceutics, Faculty of Pharmacy, Universitas Gadjah Mada, Sekip Utara, Yogyakarta, Indonesia

Tel +6281328685900

Email wahyuni_apt@ugm.ac.id
Purpose: It has been widely acknowledged that non-adherence to medication among people with type 2 diabetes is a significant problem worldwide. Studies have suggested that nonadherence to medication may be caused by the complexity of issues surrounding medication use which further created burdens related to medication. However, studies on this topic in the Indonesian context were still limited. This study aimed to understand the experiences of people with type 2 diabetes in medication-taking and explore any practical issues that potentially affect their behavior when taking medication.

Methods: Qualitative phenomenological study with semi-structured interviews was applied. The participants were purposefully recruited and selected from some primary healthcare facilities in Yogyakarta Province. The eligibility criteria included: diagnosed with type 2 diabetes by healthcare professionals for at least six months and were able to comprehend information. Information about the study was explained, and written informed consent was collected. The interviews were recorded, transcribed verbatim, and analyzed with a deductive qualitative content analysis method.

Results: Fifty-one people with type 2 diabetes were involved in this study. Most of the participants were between 40 and 59 years old, and many of them were female and housewives. The thematic analysis found some practical issues that affected people's behavior in taking type 2 diabetes medication. These included individual's mealtime, characteristics of the medications, accessibility of healthcare services, experiences of side effects and social activities.

Conclusion: The practical issues identified in this study can be resolved by improving the role of healthcare providers in managing people with diabetes. Future research needs to be conducted to evaluate the effectiveness of interventions developed based on understanding of the practical factors identified.

Keywords: people's experiences with medications, medication adherence, type 2 diabetes, Indonesia

\section{Introduction}

Indonesia, as the fourth-largest population in the world, has more than 10 million people living with diabetes. ${ }^{1}$ Most people with diabetes in Indonesia have type 2 diabetes. $^{2}$ They show poor glycemic control, which may further increase the prevalence of diabetes complications. ${ }^{2}$ A higher medical cost is needed to treat diabetes-related complications, which may further hinder the Universal Health Coverage (UHC) program in Indonesia. ${ }^{3}$ 
Poor glycemic control in people with diabetes is associated with poor adherence to treatment. ${ }^{4}$ Numerous determinants of medication adherence have been identified through both qualitative and quantitative studies in a wide variety of country settings. ${ }^{5-10}$ Many systematic reviews focused on factors affecting medication adherence have also been conducted. ${ }^{11-15} \mathrm{~A}$ review of systematic reviews conducted by Kardas, Lewek, and Matyjaszczyk $^{11}$ found 771 determinants of medication adherence classified further into five dimensions, according to the World Health Organization: ${ }^{16}$ socio-economic factors, healthcare team and system-related factors, condition-related factors, therapy-related factors, and patientrelated factors. Recently, Horne, Cooper, Wileman, Chan ${ }^{17}$ categorized factors that influence medication adherence into perceptual and practical factors. Perceptual factors included some internal cognitive variables such as people's beliefs and perceptions about the disease and treatment, while practical factors included factors from the external environment relating to the individual, treatment, or society which can affect behavior such as characteristics of the medication, accessibility of the medication, and the structure of the healthcare system. $^{17,18}$ A research by Clifford, Barber, Horne ${ }^{19}$ showed that people with perceptual factors tend to be intentional non-adherers, while people with practical factors tend to be unintentional non-adherers. Therefore, identifying practical factors influencing medication nonadherence is an important first step to improve medication adherence as unintentional non-adherers are more easily to be changed compared to intentional non-adherers. ${ }^{18}$

Although studies about medication adherence in people with diabetes in the Indonesian context are limited, some studies have explored perception factors that influence people's behavior in taking diabetes medications, including their perception about the disease and treatment. ${ }^{20,21}$ Many people favored traditional medicines as they believed that the traditional medicines were able to cure the disease. ${ }^{20,22}$ However, practical issues surrounding the use of medications for diabetes in Indonesia have not been explored yet. This research aimed to explore any practical issues that potentially affect medication-taking behaviors of people with diabetes in the Indonesian context. Understanding practical factors that influence adherence to medications in the specific Indonesian context is important to establish intervention focused on the factors identified.

\section{Methods}

\section{Study Design}

A qualitative study with face-to-face semi-structured interviews was conducted. This study was designed qualitatively as we aimed to get a deeper understanding of the people's experiences. Within the qualitative design, we applied a phenomenological perspective as we focused on exploring lived experiences of people about a phenomenon. ${ }^{23}$ In health research, the phenomena studied might be related to people's health and illness, health care, or health delivery services that are subjectively understood, practiced or experienced. ${ }^{24}$ In this research, the phenomenon studied was people's experiences related to the use of medications for diabetes.

\section{Study Locations and Participant Recruitments}

This study was conducted in Yogyakarta Province, Indonesia. Yogyakarta Province is located on Java Island, the most densely populated island inhabited by more than 151 million people or about $56 \%$ of the total population of Indonesia. ${ }^{25}$ Potential participants were recruited from community health centers (Puskesmas) located in Gunung Kidul Regency, and Yogyakarta City. Under the Universal Health Coverage (UHC) scheme, most people with diabetes received care from community health centers (Puskesmas). Therefore, we expected that the results of this study represent the wider people with diabetes in Indonesia.

The inclusion criteria of participant included: have been diagnosed with type 2 diabetes by health professionals for at least six months and were able to comprehend information. In the Indonesian context, the majority of people with diabetes who sought care and were diagnosed by health care providers received diabetes medications. This may relate to the fact that most people with diabetes in Indonesia sought care from health care providers when they experienced diabetes-related symptoms or had very high blood glucose levels. ${ }^{21}$ Potential participants with health education background or work at the health care facilities were excluded. People with higher knowledge of health and medications tended to adhere more to medications. ${ }^{26}$

As is the nature of a qualitative study, the potential participants were purposively selected according to the inclusion and exclusion criteria. Potential participants were screened for eligibility from a list of people with 
type 2 diabetes registered at the community health centers by the researchers (KKS and FPD). People with diabetes registered in the community health centers involved in this study were scheduled to have regular check-up and refill the medications once a month. Therefore, the potential participants were invited to participate verbally when they came to the community health centers for this regular check-up. The information about the study was explained, and they were asked to sign the consent forms if they agreed to participate.

\section{Data Collection}

The data were collected in August - December 2019. The interview guideline consisted of four main questions that may be expanded on participants' responses to the questions. We designed this study and developed the questions based on the conceptual model of Patients' Lived Experiences with Medicines (PLEM) developed by Mohammed, Moles, Chen. ${ }^{27}$ This conceptual model suggested that people's behaviors in taking the medications might be influenced by medication-related burdens and medication-related beliefs. ${ }^{27}$ When we designed this study, a framework specifically address the Perceptions and Practicality Approach (PAPA) developed by Horne, Cooper, Wileman, Chan $^{17}$ has not been published yet. Therefore, we used PLEM model ${ }^{27}$ with the concept of medication-taking burdens and medication-related beliefs to differentiate between practical and perceptual factors that may influence medication-taking practice. Since we focused only on practical barriers, we used the concept of medication-related burdens described by Mohammed, Moles, $\mathrm{Chen}^{27}$ for developing the questions.

The main questions were as follows: 1) Could you please tell me about your experiences of taking medications for diabetes? 2) What are the barriers or difficulties you experience in taking medications? 3) What do you think about the prescribed medications for diabetes? 4) Please tell me about your experiences in accessing the health care providers or health professionals you go to for diabetes treatment. During the introductory part of the interviews, the types of medications received were also asked to ensure that the participants took medications for diabetes.

The individual face-to-face interviews were conducted by the second and third authors (KKS and FPD) in Bahasa Indonesia (Indonesian national language). The interviews took place in the community health center (Puskesmas) after the participants received health care services for diabetes. Each interview lasted for about thirty minutes until one hour.

\section{Data Analysis}

The interviews were audio-recorded and transcribed verbatim in the original language (Bahasa Indonesia). Data analysis was conducted with these original transcripts. Translation into English was done by the first and fourth authors (AWW and NNW) with the help of a translator fluent in both Bahasa Indonesia and English when we prepared the manuscript.

Qualitative content analysis with a deductive approach was applied to analyze the data. ${ }^{28}$ Deductive approach was chosen as we aimed to find the data in the Indonesian context based on the established concept. The analysis process involved three stages: a preparation stage, including understanding the data as a whole; followed by an organization stage, including developing a categorization matrix and coding the data according to the categories; and finally, a reporting phase. $^{28}$ Open Code 4.03 software $^{29}$ was used in data analysis.

Two researchers (KKS and FPD) analyzed the transcripts independently. This process was initiated during the data collection period and continued until the researchers could not identify newer codes with the addition of a new respondent (data saturation), and the data collection process was then finalized. ${ }^{30}$ After all analyses were completed independently, meetings between the coders were made to find similarities and differences and discuss any discrepancies. To increase the trustworthiness of the findings, discussions involving all research team (all authors) were held to finalize the coding process. Agreement on the results of the coding process was reached before the results were interpreted.

\section{Ethics Approval}

Ethics approval was sought and granted by the Ethics Committee at the Faculty of Dentistry, Universitas Gadjah Mada, with the number of approval 00178/ KKEP/FKG-UGM/EC/2019. The study was conducted according to the principles outlined in the Declaration of Helsinki. ${ }^{31}$ Information for participants was explained, and written informed consent was collected. As an appreciation to participants, souvenirs were provided. Participant consent included publication of anonymized responses. All personal identifiers have been removed so the participants described cannot be identified through details of the story. 


\section{Results}

Fifty-one people with diabetes participated in this study (Table 1). Most of the participants were between 40 and 59 years old, and many of them were female and housewives. The education levels of participants varied, with some of them, have no formal education. In terms of disease experiences, most participants were first diagnosed at the age of 40-60 years and have had the disease for less than ten years. In terms of medication, forty-eight participants received oral antidiabetics, and three participants received a combination of oral antidiabetics and insulin pens. Most participants were prescribed with 2-3 routine medications, including medication for diabetes and other comorbidities.

The results of this study described some practical issues from the participants' point of view that influence their behavior in taking medications. We categorized these issues according to the concept of medication-related burdens framework that we used in designing the study: medication-related daily routine, medication characteristics, healthcare and medication, medication adverse events, medication and social burdens. ${ }^{27}$ Table 2 presents sample quotes corresponding to these categories.

\section{Medication-Related Daily Routine: Individual Mealtime}

Many participants reported that they found it difficult to follow the medications instruction as they had a different mealtime schedule. Instead of altering their mealtime to follow the schedule of medication-taking, they modified their medication-taking to follow their daily habit of eating. They understood that they should take medications routinely, for example, three times a day at mealtime: breakfast, lunch, and dinner. However, many of them said that their mealtime is often not the same every day, or they did not have a specific eating schedule. This had led them to modify their medications they were taking to match their mealtime.

\section{Medication Characteristics}

Most participants in this study received oral antidiabetics, and three of them received a combination of oral antidiabetics and insulin pens. Although most participants who received oral antidiabetics did not report any problems in taking their medications, some mentioned that metformin was quite big enough to swallow.

Three participants who were prescribed with insulin pen reported some practical problems related to the use of the
Table I Characteristics of Participants

\begin{tabular}{|c|c|c|}
\hline \multirow{2}{*}{ Characteristics } & \multicolumn{2}{|c|}{ Participants } \\
\hline & Number & Percentage (\%) \\
\hline \multicolumn{3}{|l|}{ Gender } \\
\hline Male & 23 & 45 \\
\hline Female & 28 & 55 \\
\hline \multicolumn{3}{|l|}{ Age (years) } \\
\hline $20-39$ & 2 & 4 \\
\hline $40-59$ & 37 & 73 \\
\hline $60-79$ & 12 & 23 \\
\hline \multicolumn{3}{|l|}{ Education } \\
\hline No formal education & 10 & 20 \\
\hline Elementary school & 14 & 27 \\
\hline Junior high school & 14 & 27 \\
\hline Senior high school & 6 & 12 \\
\hline Tertiary education & 7 & 14 \\
\hline \multicolumn{3}{|l|}{ Occupation } \\
\hline Housewives & 13 & 45 \\
\hline Small-scale farmers & 12 & 23 \\
\hline Employees & 10 & 20 \\
\hline Civil servants & I & 2 \\
\hline Retired & 3 & 6 \\
\hline Unemployed & 2 & 4 \\
\hline \multicolumn{3}{|l|}{ Had diabetes for (years) } \\
\hline Less than 5 & 26 & 51 \\
\hline $5-10$ & 19 & 37 \\
\hline More than 10 & 6 & 12 \\
\hline \multicolumn{3}{|l|}{ Age at diagnosis (years) } \\
\hline Less than 40 & 6 & 12 \\
\hline $40-49$ & 22 & 43 \\
\hline $50-60$ & 23 & 45 \\
\hline \multicolumn{3}{|l|}{$\begin{array}{l}\text { Type of diabetes medication } \\
\text { prescribed }\end{array}$} \\
\hline Oral antidiabetics & 48 & 94 \\
\hline $\begin{array}{l}\text { Combination of oral antidiabetics } \\
\text { and insulin pens }\end{array}$ & 3 & 6 \\
\hline \multicolumn{3}{|l|}{$\begin{array}{l}\text { Number of routine medications } \\
\text { received }\end{array}$} \\
\hline I & 10 & 20 \\
\hline 2 & 24 & 47 \\
\hline 3 & 12 & 23 \\
\hline 4 & 2 & 4 \\
\hline 5 & 3 & 6 \\
\hline
\end{tabular}

pen. These included dependency on other people to inject the insulin, the experience of pain at the injection site, and proper storage of insulin. Participants reported that although they were able to inject insulin, they were not confident enough to do it well. They often asked their family members to do that. 
Table 2 Themes and Their Corresponding Sample Quotes Identified in This Study

\begin{tabular}{|c|c|}
\hline Themes & Sample Quotes \\
\hline \multirow[t]{2}{*}{ Individual mealtime } & $\begin{array}{l}\text { "Because I am a [small scale] farmer, so I have to go to the rice field in the morning, I do not have time for breakfast. } \\
\text { Therefore, when I am at home, I take the morning medication, but when I have to go to the rice field, I take } \\
\text { medication at } 10 \text { or II AM as I just had my [first] meal at that time" (P9). }\end{array}$ \\
\hline & "Usually, I skip the after-lunch dose because I am busy working, so I skip my lunch" (P23). \\
\hline \multirow[t]{5}{*}{$\begin{array}{l}\text { Characteristics of } \\
\text { medications }\end{array}$} & $\begin{array}{l}\text { "Yes, the big one is difficult to swallow; I cannot swallow it with water. Sometimes I use banana to make it easy to } \\
\text { swallow. That makes me feel like I do not want to take that medication" (P5). }\end{array}$ \\
\hline & $\begin{array}{l}\text { "For me, using insulin is not easy, and I need to ask for help. Yes, I can do that by myself, but it should be injected by } \\
\text { others in order to hold and insert the pen upright" (PI8). }\end{array}$ \\
\hline & $\begin{array}{l}\text { "Yes, because of the pain, I sometimes skip the dose. I have had insulin for a long time, so that I have injected insulin } \\
\text { to every possible site, and because of the injection, the skin becomes thick ... and it is hurt injecting insulin to the } \\
\text { thick skin, sometimes the needles get bent because of the thickness of injection sites" (PI7). }\end{array}$ \\
\hline & $\begin{array}{l}\text { "The problem is the needles. I received three insulin pens but was only given one needle, so I protested and } \\
\text { requested for more needles. Finally, I was given } 6 \text { [needles]. For more needles, we have to buy. It is about IDR } 3500 \\
{[0.24 \text { USD] for one needle. It is also hard to find the needles in pharmacies around here; we have to go to }} \\
\text { a pharmacy in Piyungan [farther away] to buy this" (PI7). }\end{array}$ \\
\hline & "Yes, the doctor told me that insulin should be stored at the refrigerator, but I do not have a refrigerator at home" (PI7) \\
\hline \multirow[t]{3}{*}{$\begin{array}{l}\text { Accessibility of health care } \\
\text { services }\end{array}$} & $\begin{array}{l}\text { "When I do not have time to go to Puskesmas, I went to a [community] pharmacy. In the pharmacy, I checked my } \\
\text { blood glucose level, dan bought the medications there, yes, without a doctor's prescription" (P2I). }\end{array}$ \\
\hline & $\begin{array}{l}\text { "Yes, it is far away to get there [the hospital], and at the hospital, there is always a long queue. I have to leave home } \\
\text { at } 7 \text { AM, and at the hospital until } 4 \text { PM, yes, a very long queue" (PI2). }\end{array}$ \\
\hline & $\begin{array}{l}\text { "It is difficult to come to Puskesmas [a community health centre] regularly, because of my job. I have to work } \\
\text { every day and it is difficult to take a sick leave every month" (P50). }\end{array}$ \\
\hline \multirow[t]{2}{*}{ Experiences of side effect } & $\begin{array}{l}\text { "When I took one tablet of glibenclamide, I felt like having no energy, felt like about to faint. I then drank a glass of } \\
\text { sweet tea, and it is gone. After that, I only took a half of that tablet, yes, without telling the doctor" (P7). }\end{array}$ \\
\hline & $\begin{array}{l}\text { "The doctor added another medication, glimepiride } 2 \mathrm{mg} \text {, and every time I took that medication, I experienced } \\
\text { weakness, so I stopped taking that medication" (P42). }\end{array}$ \\
\hline \multirow[t]{2}{*}{$\begin{array}{l}\text { Medication related social } \\
\text { burdens }\end{array}$} & $\begin{array}{l}\text { "If my neighbors held a traditional ceremony, such as a wedding, I went to help them preparing food, and those will take } \\
\text { a whole day. I often forgot to bring my medications with me, so I did not take my medications for a whole day" (PI). }\end{array}$ \\
\hline & $\begin{array}{l}\text { "Last week, I did not take my medications for } 2 \text { days in a row as my family had a traditional ceremony. I was busy } \\
\text { organizing that event, so I skipped taking the medication" (P3 I). }\end{array}$ \\
\hline
\end{tabular}

Therefore, the use of insulin depended on the availability of other family members at home. Participants also experienced skin thickness at insulin injection sites, and this thickness triggered pain when the insulin pen was injected. Because of these, the participants sometimes skipped the insulin dose.

Another impractical problem of using insulin pen was the availability of pen needles. Insulin pens were covered by the Universal Health Coverage (UHC), but the needles of the pen were not included in the scheme. People with diabetes were provided with a very limited number of needles for a single pen. One participant mentioned that she was given only one needle for three insulin pens she received for a month course of medication. They need to pay if they want additional needles. Therefore, most of them reused this limited number of needles over time. This was not recommended; however, for people who could not afford the needle, this was practiced. They also mentioned the lack of availability of insulin needles in pharmacies close to their home.

Problems related to proper storage of the insulin pens also emerged. One participant mentioned that she stored the insulin pens unrefrigerated as she did not have a refrigerator at home. This participant was given three pens of one type of insulin for a month course of medication. Therefore, ideally, the unopened pens were stored in the refrigerator. 


\section{Healthcare and Medication: Accessibility of Health Care Services}

People with diabetes in Indonesia were commonly provided with diabetes care in community health centers (Puskesmas) located nearest to their home. However, some participants reported problems in accessing the Puskesmas. Many other participants mentioned that the problem was not the access to the health care facilities, but it was their availability to regularly go to Puskesmas for a health check-up. Routine health care services in Puskesmas are available during office hours, weekdays. Many participants reported that they were busy working during weekdays so that they could not regularly attend the healthcare services in Puskesmas. When they were not able to go to Puskesmas, some of them explained further that they always have their medication left, so they continue taking the leftover medications. This indicated that many participants do not take medications as prescribed. Some others mentioned that when they did not come to Puskesmas, they went to a community pharmacy to buy medications (without a prescription).

The other problem of accessibility was mentioned by participants who were referred to secondary level health facilities. Under the UHC management, people with diabetes received regular care from primary health care providers (Puskesmas). However, when people with diabetes need medications that are not available at the primary care facilities, for example, insulin, or need more specialist care, they will be referred to the secondary health care facilities. Most secondary health providers are hospitals that are located in the city center. For some people who live in more rural areas, accessing the hospitals was not easy. Participants who received insulin pens reported the problems related to transportation to the hospitals and long waiting times at the hospitals.

\section{Medication Adverse Events}

Some participants experienced adverse effects or any inconvenience after taking medications. Many of them reported having shakiness, excess sweating or heart palpitations after taking medications. After experiencing side effects, some of them stopped using the medications or modified the dosage of the medications by themselves, without reporting it to the doctor.

\section{Medication and Social Burdens}

Some participants mentioned that they always had their medications with them when they went out of their house.
However, many others reported that they often forgot to take medications when they were busy with social activities, such as family events, social gatherings, or went out of town.

\section{Discussion}

This study showed that most participants experienced some practical issues related to medication use. These issues might burden the participants, which further affected their behavior in taking medications.

The issues related to the daily routine of using medications found in this study were related to incorporating the medications use into daily mealtime. Most participants in this study adjusted the medications instruction to match their mealtime. Similar findings were also reported by Frandsen, Kristensen, ${ }^{32}$ that people with diabetes in European countries and the USA also found it difficult to follow the advice on diet and lifestyle changes, including eating at a regular time and not missing meals. Having regular meals is recommended for people with diabetes to minimize fluctuation of blood glucose levels as extremely low and high blood glucose levels negatively affect diabetes outcomes. ${ }^{33}$ A study also reported that eating one large meal a day increased insulin resistance and glucose intolerance compared to three smaller meals. ${ }^{34}$ A larger number of small meals were also recommended for improving diet quality and lowering Body Mass Index. ${ }^{35}$ This implies that people with diabetes in Indonesia should be provided with more detailed advice on having regular meals to maximize their diabetes outcomes. Research in Japan has suggested that people with a perception of "living an orderly life" had good adherence to medications. ${ }^{36}$

Characteristics of the medications were also found to hinder the participants in this study from taking the medications regularly. People with diabetes who find it difficult to swallow metformin often stop or skip the dose. Another practical difficulty was related to the use of insulin pens. Treatment complexity and convenience have been widely recognized to affect adherence to medications. ${ }^{37-39}$ It has been suggested that decreasing the frequency of daily doses and using insulin pens instead of insulin vial may improve adherence. ${ }^{37,39}$

However, in the context of Indonesia, the use of insulin pens may provide further burden related to accessibility and cost. Under the UHC management, the insulin pens were only available at secondary levels of health care, ${ }^{40}$ of which are commonly located further away from the people's homes. The financial burden related to the use of 
insulin comes from the cost of the needles, as the needles were not included in the UHC scheme. Limited availability of insulin pen needles has led the people with diabetes in this study to reuse the needles repeatedly. This practice may increase the risk of contamination and pain at the injection site. ${ }^{41}$ Other studies recommended that insulin pen needles may be reused up to five times to minimize the risk of lipohypertrophy. ${ }^{42,43}$ These practical problems related to insulin pens quite burdensome for some people with diabetes, particularly those who live in more rural areas and low socioeconomic status. These may imply that the Indonesian government should increase access to insulin pens and increase the number of needles covered by the UHC scheme, particularly for people with low socioeconomic status.

Another concern about insulin pens is related to their proper storage as one participant did not have a refrigerator to store the unused insulin. The FDA recommended that unopened or opened insulin and may leave unrefrigerated at between $59^{\circ} \mathrm{F}$ and $86^{\circ} \mathrm{F}\left(15^{\circ} \mathrm{C}\right.$ and $\left.30^{\circ} \mathrm{C}\right)$ for up to 28 days. ${ }^{44}$ Research has shown that a higher temperature of insulin storage (at $32^{\circ} \mathrm{C}$ to $37^{\circ} \mathrm{C}$ ) decreased the effect of insulin in reducing blood glucose levels. ${ }^{45}$ Indonesia is a tropical country, and the daily temperature may reach more than $30^{\circ} \mathrm{C}$. Health practitioners in Indonesia should provide detailed information related to insulin pens storage. In cases where patients do not have a refrigerator, the health professionals should limit the number of insulin pens for each visit or provide another solution to overcome the problem of insulin storage.

The problem of accessing primary health care services was also reported in this study. The community healthcare services (Puskesmas) only provided services during working days, and this limited the number of people with diabetes who could not have work-leave to go to Puskesmas. In the Indonesian context, as mentioned by many participants in this study, they need to spend a whole day at the primary healthcare facilities because of the long queue. Some of them, then, buy the medications from pharmacies (without a prescription). According to regulations in Indonesia, medications for diabetes are categorized as prescription-only medications. However, in practice, some people with diabetes found it was easy to buy medications from community pharmacies without prescription, as the pharmacies were easily accessed from their homes. Although this practice violated the regulations, leaving people with diabetes without any medications was also problematic. This may imply that the
Indonesian government should increase health care services and access to medications, particularly for diabetes, by collaborating with community pharmacies. A recent review assessing pharmacist-led chronic disease intervention showed that community pharmacists were able to improve clinical outcome in a number of chronic diseases, including diabetes. ${ }^{46}$ Collaboration of community pharmacist and primary health care services has also shown to be effective in improving adherence to diabetes management. ${ }^{47}$ In the Indonesian context, the community pharmacists were mainly utilized for medication dispensing, ${ }^{48}$ although the 2016 Standard for Pharmaceutical Care in Community Pharmacy emphasized the need for community pharmacist involvement in managing chronic illness. ${ }^{49}$ Research has also shown that many pharmacists in Indonesia believed that their roles should be extended to include the management of people with chronic illness. ${ }^{50}$

Another practical issue that may affect medicationtaking behavior was related to adverse effect. A large body of literature has shown that experiences of adverse effects have led to discontinuing the medications. ${ }^{37-39,51}$ Social activities may also affect people's behavior in taking medications. Many participants in this study mentioned that they often skipped taking medications when they were busy with social activities, such as family gathering or other social activities. Many studies have also demonstrated that social life impacted the use of medication. $^{27}$

The overall findings of this study align with some practical barriers identified by, ${ }^{18}$ including formulation, instruction for use, capability, medication supply and social environment. These practical issues may lead to unintentional non-adherence to diabetes medications. ${ }^{19}$ Most of the practical issues identified can be resolved by improving the role of health care providers in managing people with diabetes. However, the health care services for people with diabetes in primary health care facilities (Puskesmas) in Indonesia were mainly provided by physicians. Consequently, they were often overburdened with a large number of patients, which may lead to limited time spent talking to the patients. ${ }^{52}$ Therefore, initiating collaboration with community pharmacists for managing chronic illnesses is necessary to provide more detailed information and monitor the outcomes of people with diabetes. Medication Therapy Management (MTM) is pharmacist-led professional services that have been implemented for diabetes management worldwide. ${ }^{53}$ The 
implementation of MTM has shown effective in improving outcomes, ${ }^{53}$ and reducing patient out-of-pocket medication cost. $^{54}$

\section{Limitations}

The interviews were conducted in the community health centers (Puskesmas) after the participants receiving health care services. This method was chosen as in Indonesia, particularly in more rural areas, it is quite challenging to find participants' homes based on their registered address. However, this method may limit the interview process, as the place may often be inconvenient for face-to-face interviews. The findings of this study were based on the perception of people with diabetes in Yogyakarta Province who attended community health centers. This study involved 51 respondents, and this sample size is acceptable in qualitative research. More than half of participants, however, were female and housewife. This may relate to the finding of this study that the availability of healthcare services in Puskesmas, which was only during office hours and weekdays, became one of the barriers for the people with diabetes to access Puskesmas. Therefore, most people who were able to regularly attend the Puskesmas were female and housewife. This limitation may imply that it is important to be cautious in explaining the results among people with diabetes in Indonesia from diverse socio-demographic characteristics. Practical barriers to medication adherence might differ by regional location, the health care providers the people attend to, and socio-demographic characteristics. Future research needs to be done to explore practical barriers of adherence to diabetes medication among people in different regions, different healthcare providers, and more diverse sociodemographic characteristics of respondents. Despite these limitations, the findings of this study can inform interventions that need to be established to improve people's adherence to diabetes medications.

\section{Conclusion}

Adherence to medications of people with type 2 diabetes in Indonesia may be affected by several practical issues, including individual's mealtime, characteristics of medications, accessibility of health care services, experiences of side effects and social activities. The findings of this study provide some implications for clinical practice in Indonesia. Providing services during weekends or holidays, increasing the availability of insulin pens and needles in the community health centers may improve people's access to medications. Improving patient-health care provider communications is also essential to evaluate the effectiveness and safety of the medication prescribed and improve people's knowledge and skills on how to incorporate the medication use into their daily habit. Interprofessional collaboration to manage chronic illness needs to be initiated. Future studies need to be conducted involving a more diverse community in Indonesia. The effectiveness of the interventions established based on the understanding of the practical factors identified also needs to be evaluated.

\section{Acknowledgments}

The authors wish to acknowledge the participants and the health professionals in Puskesmas in study locations.

\section{Disclosure}

The authors report no conflicts of interest in this work.

\section{References}

1. International Diabetes Federation. IDF diabetes atlas - Eighth edition 2017. International Diabetes Federation; 2017: Available from:https:// diabetesatlas.org/upload/resources/previous/files/8/IDF_DA_8e-ENfinal.pdf . Accessed January 3, 2019.

2. Soetedjo NNM, McAllister SM, Ugarte-Gil C, et al. Disease characteristics and treatment of patients with diabetes mellitus attending government health services in Indonesia, Peru, Romania and South Africa. Trop Med Int Health. 2018;23(10):1118-1128. doi:10.1111/ tmi. 13137

3. Agustina R, Dartanto T, Sitompul R, et al. Universal health coverage in Indonesia: concept, progress, and challenges. Lancet. 2019;393 (10166):75-102. doi:10.1016/S0140-6736(18)31647-7

4. Egede LE, Gebregziabher M, Echols C, Lynch CP. Longitudinal effects of medication nonadherence on glycemic control. Ann Pharmacother. 2014;48(5):562-570. doi:10.1177/1060028014526362

5. Huang Y-M, Pecanac KE, Shiyanbola OO. "Why am i not taking medications?" Barriers and facilitators of diabetes medication adherence across different health literacy levels. Qual Health Res. 2020;30 (14):2331-2342. doi:10.1177/1049732320945296

6. Shiyanbola OO, Brown CM, Ward EC. "I did not want to take that medicine": African-Americans' reasons for diabetes medication nonadherence and perceived solutions for enhancing adherence. Patient Prefer Adherence. 2018;12:409-421. doi:10.2147/PPA.S152146

7. Sapkota S, Brien JAE, Aslani P. Nepalese patients' perceptions of treatment modalities for type 2 diabetes. Patient Prefer Adherence. 2016;10:1777-1786. doi:10.2147/PPA.S113467

8. Kumar K, Greenfield S, Raza K, Gill P, Stack R. Understanding adherence-related beliefs about medicine amongst patients of South Asian origin with diabetes and cardiovascular disease patients: a qualitative synthesis. BMC Endocr Disord. 2016;16(1). doi:10.1186/s12902-016-0103-0

9. Alqarni AM, Alrahbeni T, Qarni AA, Qarni HMA. Adherence to diabetes medication among diabetic patients in the Bisha governorate of Saudi Arabia - a cross-sectional survey. Patient Prefer Adherence. 2018;13:63-71. doi:10.2147/PPA.S176355

10. Aminde LN, Tindong M, Ngwasiri CA, et al. Adherence to antidiabetic medication and factors associated with non-adherence among patients with type-2 diabetes mellitus in two regional hospitals in Cameroon. BMC Endocr Disord. 2019;19(1):35. doi:10.1186/s12902019-0360-9 
11. Kardas P, Lewek P, Matyjaszczyk M. Determinants of patient adherence: a review of systematic reviews. Front Pharmacol. 2013;4:91. doi:10.3389/fphar.2013.00091

12. Sohal T, Sohal P, King-Shier KM, Khan NA. Barriers and facilitators for type-2 diabetes management in South Asians: a Systematic Review. PLoS One. 2015;10(9):e0136202. doi:10.1371/journal. pone. 0136202

13. Krass I, Schieback P, Dhippayom T. Adherence to diabetes medication: a systematic review. Diabet Med. 2015;32(6):725-737. doi:10.1111/dme.12651

14. McSharry J, McGowan L, Farmer AJ, French DP. Perceptions and experiences of taking oral medications for the treatment of type 2 diabetes mellitus: a systematic review and meta-synthesis of qualitative studies. Diabet Med. 2016;33(10):1330-1338. doi:10.1111/ dme. 13152

15. Gellad WF, Grenard JL, Marcum ZA. A systematic review of barriers to medication adherence in the elderly: looking beyond cost and regimen complexity. Am J Geriatr Pharmacother. 2011;9(1):11-23. doi:10.1016/j.amjopharm.2011.02.004

16. World Health Organization. Adherence to Long Term Therapies, Evidence for Action. Geneva: World Health Organization; 2003.

17. Horne R, Cooper V, Wileman V, Chan A. Supporting adherence to medicines for long-term conditions: a perceptions and practicalities approach based on an extended common-sense model. Eur Psychol. 2019;24(1):82-96. doi:10.1027/1016-9040/a000353

18. Chan AHY, Cooper V, Lycett H, Horne R. Practical barriers to medication adherence: what do current self- or observer-reported instruments assess? Front Pharmacol. 2020;11:572. doi:10.3389/ fphar.2020.00572

19. Clifford S, Barber N, Horne R. Understanding different beliefs held by adherers, unintentional nonadherers, and intentional nonadherers: application of the necessity-concerns framework. J Psychosom Res. 2008;64(1):41-46. doi:10.1016/j.jpsychores.2007.05.004

20. Widayanti AW, Norris P, Heydon S, Green JA. Medicine taking behaviours of people with type 2 diabetes in Indonesia: a qualitative study. Int J Clin Pharm Net. 2020;42(1):31-39. doi:10.1007/s11096-019-00933-0

21. Widayanti AW, Heydon S, Norris P, Green JA. Lay perceptions and illness experiences of people with type 2 diabetes in Indonesia: a qualitative study. Health Psychol Behav Med. 2020;8(1):1-15. doi:10.1080/21642850.2019.1699101

22. Alfian SD, Sukandar H, Arisanti N, Abdulah R. Complementary and alternative medicine use decreases adherence to prescribed medication in diabetes patients. Ann Trop Med Public Health. 2016;9 (3):174-179. doi:10.4103/1755-6783.179108

23. Creswell JW, Creswell JD. Research Design: Qualitative, Quantitative, and Mixed Methods Approaches. Sage publications; 2017.

24. Barbour RS. Focus Groups. In: Bourgeault I, Dingwall R, Rd V, editors. The SAGE Handbook of Qualitative Methods in Health Research. London: SAGE Publications. SAGE Publications; 2010:327-334.

25. Statistics of Indonesia. Infografis hasil sensus penduduk Indonesia 2020 [the results of Indonesia 2020 census]; 2021. Available from: https:/www.bps.go.id/website/images/Hasil-SP2020-ind.jpg. Accessed March 5, 2021.

26. Al-Qazaz HK, Sulaiman SA, Hassali MA, et al. Diabetes knowledge, medication adherence and glycemic control among patients with type 2 diabetes. Int $J$ Clin Pharm Net. 2011;33(6):1028-1035. doi:10.1007/s11096-011-9582-2

27. Mohammed MA, Moles RJ, Chen TF. Medication-related burden and patients' lived experience with medicine: a systematic review and metasynthesis of qualitative studies. BMJ Open. 2016;6(2):e010035. doi:10.1136/bmjopen-2015-010035

28. Elo S, Kyngäs H. The qualitative content analysis process. $J$ Adv Nurs. 2008;62(1):107-115. doi:10.1111/j.1365-2648.2007.04569.x
29. OpenCode 4.0 [computer program]. Sweden: University of Umeå; 2013.

30. Saunders B, Sim J, Kingstone T, et al. Saturation in qualitative research: exploring its conceptualization and operationalization. Qual Quant. 2018;52(4):1893-1907. doi:10.1007/s11135-017-0574-8

31. World Medical Association. World medical association Declaration of Helsinki: ethical principles for medical research involving human subjects. JAMA. 2013;310(20):2191-2194. doi:10.1001/ jama.2013.281053

32. Frandsen KB, Kristensen JS. Diet and lifestyle in type 2 diabetes: the patient's perspective. Pract Diabetes Int. 2002;19(3):77-80. doi: $10.1002 /$ pdi.327

33. Ruszala V. Question from practice: diabetes - missing meals and doses. Pharm J. 2013;291:57.

34. Carlson O, Martin B, Stote KS, et al. Impact of reduced meal frequency without caloric restriction on glucose regulation in healthy, normal-weight middle-aged men and women. Metabolism. 2007;56 (12):1729-1734. doi:10.1016/j.metabol.2007.07.018

35. Aljuraiban GS, Chan Q, Oude Griep LM, et al. The impact of eating frequency and time of intake on nutrient quality and body mass index: the INTERMAP Study, a population-based Study. J Acad Nutr Diet. 2015;115(4):528-536.e521. doi:10.1016/j. jand.2014.11.017

36. Hashimoto K, Urata K, Yoshida A, et al. The relationship between patients' perception of type 2 diabetes and medication adherence: a cross-sectional study in Japan. J Pharm Health Care Sci. 2019;5 (1):2. doi:10.1186/s40780-019-0132-8

37. Polonsky WH, Henry RR. Poor medication adherence in type 2 diabetes: recognizing the scope of the problem and its key contributors. Patient Prefer Adherence. 2016;10:1299-1307. doi:10.2147/PPA.S106821

38. Roborel de Climens A, Pain E, Boss A, Shaunik A. Understanding reasons for treatment discontinuation, attitudes and education needs among people who discontinue type 2 diabetes treatment: results from an online patient survey in the USA and UK. Diabetes Ther. 2020;11(8):1873-1881. doi:10.1007/s13300-020-00843-9

39. Guerci B, Chanan N, Kaur S, Jasso-Mosqueda JG, Lew E. Lack of treatment persistence and treatment nonadherence as barriers to glycaemic control in patients with type 2 diabetes. Diabetes Ther. 2019;10(2):437-449. doi:10.1007/s13300-019-0590-x

40. Indonesia Ministry of Health. Formularium Nasional (National Formulary). Jakarta: Indonesia Ministry of Health; 2019.

41. Misnikova I, Dreval A, Gubkina V, Rusanova E. The risks of repeated use of insulin pen needles in patients with diabetes mellitus. J Diabetol. 2011;2(1):2.

42. Blanco M, Hernández MT, Strauss KW, Amaya M. Prevalence and risk factors of lipohypertrophy in insulin-injecting patients with diabetes. Diabetes Metab. 2013;39(5):445-453. doi:10.1016/j. diabet.2013.05.006

43. Puder JJ, Atar M, Muller B, Pavan M, Keller U. Using insulin pen needles up to five times does not affect needle tip shape nor increase pain intensity. Diabetes Res Clin Pract. 2005;67(2):119-123. doi:10.1016/j.diabres.2004.06.001

44. U.S. Food and Drug Administration. Information regarding insulin storage and switching between products in an emergency; 2017; Available from: https:/www.fda.gov/drugs/emergency-preparednessdrugs/information-regarding-insulin-storage-and-switching-betweenproducts-emergency. Accessed August 20, 2020.

45. Vimalavathini R, Gitanjali B. Effect of temperature on the potency \& pharmacological action of insulin. Indian J Med Res. 2009;130 (2):166-169.

46. Newman TV, San-Juan-Rodriguez A, Parekh N, et al. Impact of community pharmacist-led interventions in chronic disease management on clinical, utilization, and economic outcomes: an umbrella review. Res Social Adm Pharm. 2020;16(9):1155-1165. doi:10.1016/ j.sapharm.2019.12.016 
47. Snyder JM, Ahmed-Sarwar N, Gardiner C, Burke ES. Community pharmacist collaboration with a primary care clinic to improve diabetes care. J Am Pharm Assoc. 2020;60(3):S84-S90. doi:10.1016/j. japh.2020.02.005

48. Wibowo Y, Parsons R, Sunderland B, Hughes J. An evaluation of community pharmacy-based services for type 2 diabetes in an Indonesian setting: patient survey. PeerJ. 2015;3:e1449. doi: $10.7717 /$ peerj.1449

49. Indonesia Ministry of Health. Peraturan Menteri Kesehatan No 73 tahun 2016 tentang Standard Pelayanan Kefarmasian di Apotek [Ministry of health regulation No. 73 year 2016 about standar for pharmaceutical care in community pharmacies]. Indonesia Ministry of Health; 2016.

50. Wibowo Y, Parsons R, Sunderland B, Hughes J. Evaluation of community pharmacy-based services for type-2 diabetes in an Indonesian setting: pharmacist survey. Int J Clin Pharm Net. 2015;37 (5):873-882. doi:10.1007/s11096-015-0135-y
51. Habte BM, Kebede T, Fenta TG, Boon H. Ethiopian patients' perceptions of anti-diabetic medications: implications for diabetes education. J Pharm Policy Pract. 2017;10(1):14. doi:10.1186/s40545-0170101-2

52. Williams PA, Prabandari YS, Burfeind C, Lefebvre RC, LaBresh KA. Impact of a pilot intervention to increase physician-patient communication about stroke risk in Indonesia. Health Commun. 2016;31 (12):1573-1578. doi:10.1080/10410236.2015.1082456

53. Viswanathan M, Kahwati LC, Golin CE, et al. Medication therapy management interventions in outpatient settings: a systematic review and meta-analysis. JAMA Intern Med. 2015;175(1):76-87. doi:10.1001/jamainternmed.2014.5841

54. Dodson SE, Ruisinger JF, Howard PA, Hare SE, Barnes BJ. Community pharmacy-based medication therapy management services: financial impact for patients. Pharm Pract (Granada). 2012;10(3):119-124. doi:10.4321/S1886-36552012000300001

\section{Publish your work in this journal}

Patient Preference and Adherence is an international, peer-reviewed, open access journal that focusing on the growing importance of patient preference and adherence throughout the therapeutic continuum. Patient satisfaction, acceptability, quality of life, compliance, persistence and their role in developing new therapeutic modalities and compounds to optimize clinical outcomes for existing disease states are major areas of interest for the journal. This journal has been accepted for indexing on PubMed Central. The manuscript management system is completely online and includes a very quick and fair peer-review system, which is all easy to use. Visit http:// www.dovepress.com/testimonials.php to read real quotes from published authors. 